\title{
Developing a Web-Based Shared Decision-Making Tool for Fertility Preservation Among Reproductive-Age Women With Breast Cancer: An Action Research Approach
}

Ling-Ming Tseng ${ }^{1,2}$, MD; Pei-Ju Lien ${ }^{1}$, BA; Chen-Yu Huang ${ }^{3}$, MD, PhD; Yi-Fang Tsai ${ }^{1,2}$, MD, PhD; Ta-Chung $\mathrm{Chao}^{1,2,4}$, MD, PhD; Sheng-Miauh Huang ${ }^{5}, \mathrm{PhD}$

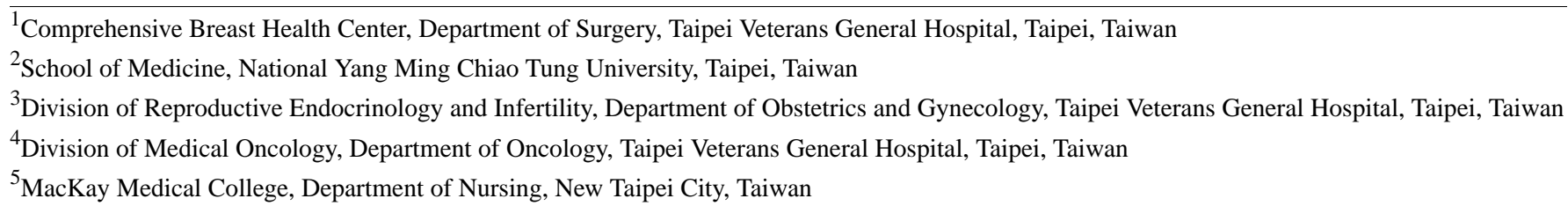

\section{Corresponding Author:}

Sheng-Miauh Huang, PhD

MacKay Medical College

Department of Nursing

No. 46, Section 3, Zhongzheng Road

Sanzhi District

New Taipei City, 252

Taiwan

Phone: 886226360303 ext 1316

Email: r910862@yahoo.com.tw

\section{Abstract}

Background: The pregnancy rate after cancer treatment for female survivors is lower than that of the general population. Future infertility is a significant concern for patients with breast cancer and is associated with a poor quality of life. Reproductive-age patients with breast cancer have safe options when choosing a type of fertility preservation method to be applied. Better information and support resources aimed at women to support their decision making are needed.

Objective: The objective of this study was to develop a web-based shared decision-making tool for helping patients with breast cancer make decisions on fertility preservation.

Methods: We used the action research cycle of observing, reflecting, planning, and acting to develop a web-based shared decision-making tool. The following four phrases were applied: (1) observe and reflect—collect and analyze the decision-making experiences of patients and health care providers; (2) reflect and plan-apply the initial results to create a paper design and modify the content; (3) plan and act-brainstorm about the web pages and modify the content; (4) act and observe-evaluate the effectiveness and refine the website's shared decision-making tool. Interviews, group meetings, and constant dialogue were conducted between the various participants at each step. Effectiveness was evaluated using the Preparation for Decision-Making scale.

Results: Five major parts were developed with the use of the action research approach. The Introduction (part 1) describes the severity of cancer treatment and infertility. Options (part 2) provides the knowledge of fertility preservation. The shared decision-making tool was designed as a step-by-step process (part 3) that involves the comparison of options, patient values, and preferences; their knowledge regarding infertility and options; and reaching a collective decision. Resources (part 4) provides information on the hospitals that provide such services, and References (part 5) lists all the literature cited in the website. The results show the web-based shared decision-making meets both patients' and health providers' needs and helps reproductive-age patients with breast cancer make decisions about fertility preservation.

Conclusions: We have created the first web-based shared decision-making tool for making fertility preservation decisions in Taiwan. We believe female patients of reproductive age will find the tool useful and its use will become widespread, which should increase patient autonomy and improve communication about fertility preservation with clinicians.

Trial Registration: Clinicaltrials.gov NCT04602910; https://clinicaltrials.gov/ct2/show/NCT04602910 
(J Med Internet Res 2021;23(3):e24926) doi: 10.2196/24926

\section{KEYWORDS}

breast cancer; shared decision making; website; action research; fertility preservation

\section{Introduction}

Breast cancer is a common oncologic disease worldwide. In Taiwan, breast cancer has the highest incidence of all cancers in the female population, and the incidence of breast cancer in women of childbearing age is increasing [1]. Approximately $12 \%$ to $19 \%$ of patients are affected when they are of reproductive age [1-3]. Fertility and infertility are important concerns among reproductive-age women with breast cancer [4,5]. Infertility following cancer treatment has a recognized negative impact on the quality of life [6]. The National Cancer Institute (Taiwan) defined fertility preservation as a type of procedure used to help a person' retain the ability to have children [7]. The key point is that reproductive-age patients have more than one fertility preservation choice. Unfortunately, most patients do not have enough information to make an informed decision prior to cancer treatment. For instance, ovarian stimulation in patients with early-stage breast cancer is safe in the long term [3]. Women diagnosed with cancer who have eggs or embryos cryopreserved before anticancer treatment have good chances for successful assisted reproductive technology performance and good perinatal outcomes [8-10]. In addition, the efficacy and safety of temporary ovarian suppression with gonadotropin-releasing hormone agonist during chemotherapy might be an available option to reduce the likelihood of chemotherapy-induced primary ovarian insufficiency and to improve future fertility in premenopausal patients with early breast cancer [11]. It is worth noting that there is consensus in medical society that the long-term survival rate of the disease is not lower for any of the three types of fertility preservation [8-11]. Thus, if age, reproductive function, and the cancer stage allow, patients can choose their preferred fertility preservation method.

A previous study [12] indicated patients' decisions about fertility are multidimensional. The risk perception of pregnancy among patients with breast cancer after treatment focused on "reaching the balance of life [12]." Women treated for breast cancer applied risk-benefit perceptions to decide whether to become pregnant [12]. There are several factors related to the ability to make well-informed decisions regarding fertility preservation. First, patients with a new diagnosis of breast cancer often experience negative emotions, such as anxiety, depression, and uncertainty, due to their perceptions of life-threatening cancer [13-15]. Second, women are expected to have biological children because of the Chinese cultural belief in lineal descent from one's ancestors, which is deeply rooted among the Taiwanese people. The assignment of great importance to parenthood was directly associated with higher depression symptoms in reproductive-age women with breast cancer [16].

Additionally, some health care providers might keep silent about discussing fertility because their primary concern is getting their patients to be cancer free [17]. Patients with breast cancer lacked easily available knowledge about infertility and underestimated the possibility of infertility [18]. This requirement for information is mostly unmet. Patients do not fully understand the impact of cancer treatment and the possibility of infertility because of treatment. Finally, the space and environment of the outpatient clinic are not conducive to the discussion of private issues. Fertility concerns are not encouraged to be brought to the physicians' or nurses' attention before cancer treatment. Although women want to request further information regarding future fertility, they may hesitate even when talking to their physicians, disclosing their opinion, or showing their personal feelings.

The first Patient Autonomy Act was passed through the Legislative Yuan in Taiwan in 2015. Now, it is vital to ensure that patients have the right to know, choose, or refuse medical care, and in addition to being informed, patients can choose their medical options. All of the above can be achieved via shared decision making (SDM) [19-22]. The Joint Commission of Taiwan, which is an organization established in 1999 with funding from the Ministry of Health and Welfare, Taiwan Hospital Association, promotes the development of SDM [23]. Difficulty accessing decision aids or limited patient comprehension were common barriers to realizing shared decision making [24]. Decision aids that improve decision-related outcomes for many breast cancer treatment decisions, including surgery, radiotherapy, and endocrine and chemotherapy, are available [25]. Fertility preservation with decision aids is well-developed in some economically high-income countries, such as Australia [26], Canada [27], Netherlands [28], and the United States [29]. Therefore, we aimed to develop a web-based SDM tool for fertility preservation for patients with breast cancer. The web-based decision aid was expected to provide medical information, help the patient explore and compare treatment options, assess the patient's values and preferences, and reach a collective decision on fertility preservation.

\section{Methods}

\section{Research Design}

We applied an action research design, which is defined as an approach that involves collaboration to develop a process through knowledge-building and social change [30]. Learning by doing with the participants, including the patients, is the heart of health care action research. The action research approach is particularly relevant when treating patients with chronic diseases and complex care needs [31,32]. Previous investigators have applied action research to build web-based comics [33] or decision-aid websites [34] about breast cancer surgery in Taiwan. However, few study the decision-making and research processes for oncofertility in Asia. Therefore, the ultimate goal of this study was to find supporting evidence of the benefits to patients and families of a web-based platform that assists patients with breast cancer in the SDM for fertility preservation. 


\section{Project Team}

The SDM team was multidisciplinary, comprising a senior researcher, two surgeons, an oncologist, a gynecologist, an advanced nurse specialist, and an information technology (IT) engineer. The surgeon, oncologist, and gynecologist were responsible for gathering and reviewing existing fertility preservation literature to create easy-to-understand formats and simple graphic renderings of patients with breast cancer. The researcher and nurse specialist interviewed women and health providers to explore their experiences regarding the decision-making process. The IT engineer was responsible for informatics work related to website page design, program coding, and hosting of the website. The members involved in breast care had at least 10 years of experience. The IT engineer was a senior website designer with 5 years of work experience. The team had regular face-to-face and line meetings to prepare for and reflect on the development of the oncofertility SDM program and the community of fertility preservation practice. The SDM team was the partnership in the sense of doing together and deciding together during the research phase. The roles of the members were alternately those of initiator, educator, facilitator, coach, and finally, coauthors.

\section{Action Research Process}

A participatory action research methodology was used to facilitate the development of the SDM program for the multidisciplinary care team at the same time that a web-based SDM of fertility preservation practice was being established. The action research cycle of observing, reflecting, planning, and acting was applied in this study (Figure 1).

Because the SDM involved both health care providers and patients, we collected data from both views at the phases of observing and reflecting. Health care providers were recruited to interview and ask patients about their experiences regarding fertility. We also recruited breast cancer survivors to explore the decision-making experience of pregnancy. The reflections were viewed as a continuous dialogue among team members during the SDM program. The results of data collection and team self-evaluation of our positionality were analyzed, with the explicit recognition that this position may affect the SDM process and outcome. The evaluations were interdependent and partly based on the project team members' interpersonal, social, and institutional contexts.

During the phases of reflecting and planning, all major team members not only reviewed the health issues and evidence-based literature related to fertility preservation in patients with cancer but also discussed the SDM content based on the findings from the observe and reflect phases. Three patients were invited to participate and provide their suggestions. The initial paper-designed content of SDM for fertility preservation was formed by consensus after 6 meetings.

During the phases of planning and acting, the initial website structure was developed according to the 5 steps of SDM. Each part of the SDM was assessed for comprehensibility and usability by patients. Health care providers were asked to assess the acceptability of the SDM content. A 5-point Likert scale was used for patient and health care provider ratings for each item. If the score was less than 3 , then we modified the website content based on the user feedback from patients and health care providers.

During the phase of acting, we evaluated the effectiveness of the Preparation for Decision-Making (prepDM) scale developed by Bennett et al [35]. The Joint Commission of Taiwan also suggested the effects of SDM be evaluated in patients and health care providers. Both patients and health care providers were invited to answer 10 questions by responding with a 5-point Likert scale rating (from 1 to 5). A higher score indicated greater agree with the effect.

Figure 1. The process of action research in developing web-based shared decision-making regarding fertility preservation.

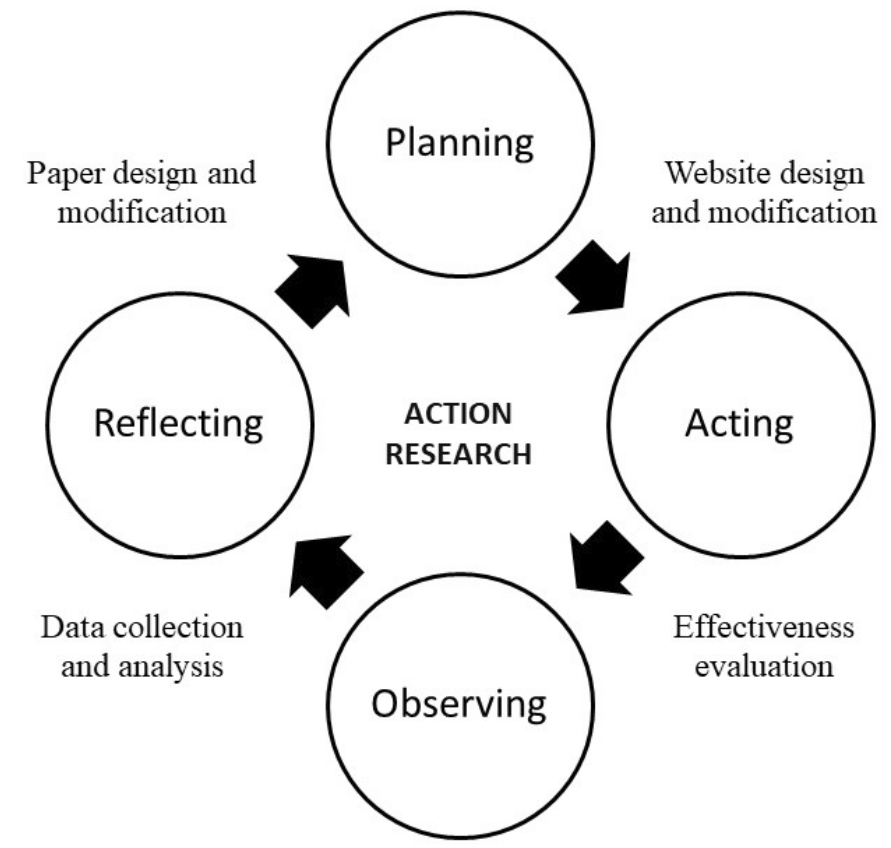




\section{Setting}

The setting was the comprehensive breast health center at Taipei Veterans General Hospital in Taipei, Taiwan. The center integrates multidisciplinary care to provide comprehensive services, including diagnosis and treatment, to achieve the purpose of patient-centric care. The health care providers included surgeons, gynecologists, Chinese medicine doctors, nurses, psychological consultants, social workers, and nutritionists. The web-based SDM for fertility preservation was linked to the hospital website.

\begin{abstract}
Analysis
In-depth interviews were done to collect and gain deep insights into the views and needs of the participants. Data collected through the face-to-face interviews were transcribed from audiorecordings to written transcripts. The content analysis method was used to analyze the data. We checked whether the categories were stable and provided sufficient depth, then multiple strategies were applied to ensure trustworthiness. The discussion and decision at the group meetings were also recorded. The effectiveness was evaluated using the prepDM scale developed by Bennett et al [35]. Statistical analyses were performed using the Predictive Analytics Suite workstation (version 18.0; IBM Corp). Individual variables were examined by percentages, means, and standard deviations.
\end{abstract}

\section{Results}

\section{Results of the Observe and Reflect Phase}

Cancer survivors $(n=16)$ were recruited to explore the decision-making experience of determining whether to have a pregnancy (from 2015 through 2016). The result showed decision making regarding fertility among women with cancer was affected by preexisting needs for children before treatment and their experience during treatment. Underestimating the possibility of infertility and a lack of knowledge of fertility preservation might cause the woman to regret her decision. (Participant names are pseudonyms.)

If I had known in advance, I could have frozen my eggs. I mean, normal eggs are taken before chemotherapy. Because it [chemotherapy] has damaged my eggs now, I can't afford another invasive examination or treatment. [Bella]
Health care providers $(n=16)$, including nurses $(n=8)$, surgeons $(n=3)$, gynecologists $(n=2)$, Chinese medicine doctor $(n=1)$, psychology consultant $(n=1)$, and social worker $(n=1)$, were also recruited to interview and ask the women about their experiences regarding fertility (from 2017 through 2018). Although most of the health care providers were concerned about the severity of the cancer and the urgency of treatment, they agreed to satisfy the women's needs and respect their choice. However, there are some barriers to be solved, such as communication blocks among the multidisciplinary team, lack of initial screening, and lack of evidence-based information regarding oncofertility.

\section{I think the empirical literature may exist, but nobody has assembled it into a simple language that the patient can understand. All we know is that it requires more manpower and material resources... [Jeff]}

\section{Results of the Reflect and Plan Phase}

After collecting the data and performing a content a qualitative content analysis, we discussed strategies to overcome the barriers. The SDM process was expected to progress step by step, according to the five essential steps of SDM developed by the Agency for Healthcare Research and Quality [36]. Reproductive-age women had insufficient knowledge regarding infertility and the types of fertility preservation. More than $96 \%$ of Taiwanese ever used the internet to search for information [37]. Hence, all project members focused the information they provided on the website on cancer treatment, infertility, and the types of fertility preservation necessary before embarking on the SDM steps. Therefore, the introduction involved the description of the severity of the cancer and its treatment and the possibility of infertility. Then, the options regarding fertility preservation were designed. The SDM part included providing comparisons of treatment and fertility preservation options, assessing each patient's values and preferences (such as cost or safety), assessing their degree of knowledge regarding infertility and fertility preservation options, and reaching a collective decision on the best option. We also linked the organizations that provide fertility preservation services in a resource section [38]. Appropriate literature was also provided in the reference section. The website structure was designed, as shown in Figure 2. All team members were assigned to fulfill this information need for the patients. The content provided in each section was reached by consensus in group meetings. 
Figure 2. Website structure. SDM: shared decision making.

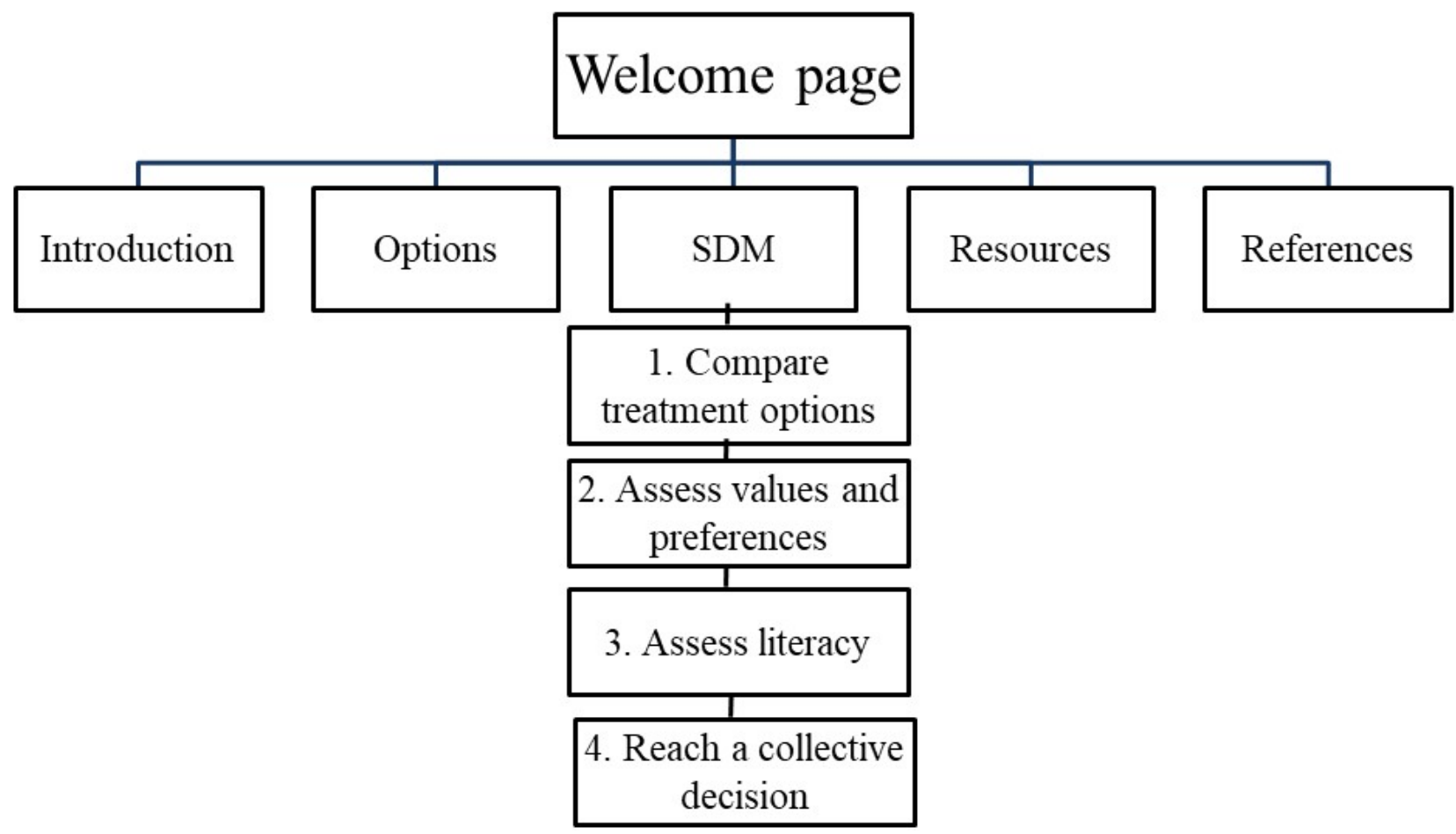

\section{Results of the Plan and Act Phase}

Upon entering the welcome page, patients are shown a clear title; for example, "I am a patient with breast cancer. How will I fulfill my dream of having a child? (Chinese: 我是乳癌病 人，怎麼圓生子夢?).” Our webpage follows a structure where the five main parts with their corresponding submenus are displayed as the user clicks on them (Multimedia Appendix 1). The five main webpage subtitles are Introduction, Options, SDM, Resources, and Reference Links. A 5-point Likert scale was used for patient and care provider ratings. Patients $(n=13)$ rated the web-based SDM for comprehensibility (mean 3.9, SD 0.9 ) and usability (mean 3.9, SD 1.1). Health care providers $(n=9)$ were also asked to assess the acceptability (mean 4.3, SD 0.8 ). If the score was less than 3 , we modified the website content based on the user feedback from patients and health care providers. For example, patients mentioned that pharmaceutical and scientific names or brand names (such as gonadotropin-releasing hormone agonist or Zoladex) are too hard to understand. Patients said it is easier to understand simpler terms like "medicine postponing menstruation" (Chinese: 注射停經針). When patients were tested on their knowledge regarding fertility preservation, some still misunderstood and felt frustrated. Hence, we provide links to help answer questions and clarify their knowledge. When all questions are answered correctly, the user can enter the next stages (Multimedia Appendix 2; Multimedia Appendix 3; Multimedia Appendix 4).

The Action Script technology for the front-end framework was Vue.js, and the back-end framework was Laravel 5 (requiring PHP 7.2). The operating system was Amazon Linux 2, while the network server was Apache 2.4. AWS EC2 hosted the web-based machine. The database was MySQL 5.7 (Amazon RDS).

\section{Results of the Act and Observe Phase}

We used a multifaceted approach to evaluate the website after the completion of the preliminary website. The SDM effectiveness of the website was evaluated using the SDM questionnaire developed by The Joint Commission of Taiwan. The participants in the evaluation consisted of 14 reproductive-age patients with breast cancer $(n=14$, prepDM: mean 4.1, SD 0.8) and 11 hospital staff ( $\mathrm{n}=11$, prepDM: mean 4.2, SD 0.7) (Table 1). Both patients and staff had the perception that the web-based SDM was effective for helping reproductive-age patients with breast cancer make fertility preservation decisions. Based on feedback from the patients and hospital care providers, we refined the options because some patients had hesitation about the website. The option "can't decide right now" was added, and qualitative and quantitative items regarding further needs were added to the survey (Multimedia Appendix 5). 
Table 1. Results of the Preparation for Decision-Making Survey scale among health care providers and patients with breast cancer.

\begin{tabular}{lll}
\hline Item & Health providers (n=11), mean (SD) & Patients (n=14), mean (SD) \\
\hline 1. Recognize decision needs to be made & $4.1(0.8)$ & $4.1(0.9)$ \\
2. Prepare my patient/you to make a better decision & $4.2(0.9)$ & $4.2(1.0)$ \\
3. Think about pros and cons of each option & $4.2(0.8)$ & $4.2(0.8)$ \\
4. Help my patient/you think about which pros and cons are most important & $4.3(0.6)$ & $4.3(0.8)$ \\
5. Know that decision depends on what matters most to my patient/you & $4.1(0.8)$ & $4.2(0.8)$ \\
6. Organize my patient's/your thoughts about decision & $4.2(0.8)$ & $3.9(1.0)$ \\
7. Think about how involved my patient/you want to be in the decision & $4.4(0.8)$ & $3.9(0.9)$ \\
8. Help my patient/you identify questions you want to ask & $4.4(0.7)$ & $4.1(0.9)$ \\
9. Talk to patient's/your doctor about what matters most & $4.3(1.0)$ & $4.1(1.0)$ \\
10. Promote health literacy/prepare you for a follow-up visit with your & $4.3(0.8)$ & $3.9(1.2)$ \\
doctor & & $4.1(0.8)$ \\
Average & $4.2(0.7)$ & \\
\hline
\end{tabular}

\section{Discussion}

\section{Principal Findings}

We used action research to create a website for the SDM model for fertility preservation among young women with breast cancer [39]. The approach consisted of four phases based on the principles of SDM. Previous SDM-related literature has highlighted the importance of the principles of informed consent and patient autonomy [19-22]. When women make a meaningful decision regarding their choice of fertility preservation, their degree of medical literacy, preferences, and a close relationship (mutual communication and understanding) between themselves and health care providers are often key challenges. Sometimes, a conflict happens between what the patients want and what the clinicians deem necessary in terms of the website during the four phases. We not only collected qualitative and quantitative data but brainstormed acceptable content for both health care providers and patients. This work implied that the SDM for fertility preservation, as guided by action research, would bridge the gap between the patients and clinicians and caters more toward the feelings and needs of the patients' minds and bodies than previous approaches. The findings were consistent with those of previous studies [33,34] for which decision-aid websites for breast cancer surgery or comics for newly diagnosed breast cancer in women were developed. Compared with the development of medical information websites, the development of web-based decision aids using action research may be more systematic and humanistic because they account for both the patients' and health care providers' perspectives and needs. When considering the participants' corresponding culture and the region in which they live, our study serves as a reference for describing how to develop decision support tools for women with breast cancer and fertility needs.

Limited health literacy is associated with poorer health outcomes and may make it difficult for cancer patients to participate in the SDM process [23]. Increasing health literacy has the potential to increase health care engagement and, subsequently, to increase the use of SDM [40]. Improving women's health literacy is a necessary strategy to promote informed consent and SDM. In Taiwan, explaining the disease condition and its related treatment is the responsibility of the attending physician. Physicians explain the disease and related treatments in colloquial language, which is a key factor in promoting patients' perceived involvement in SDM [41]. Before the SDM process, our Introduction and Options website pages provided familiar text and pictures for physicians to explain the consequences of infertility and the methods of fertility preservation. It was also easy for patients to go back and reread the pages for better understanding. Previous scholars mentioned three major SDM steps, which included exploring care or treatment options and their risks and benefits, discussing choices available, and reaching a decision about care or treatment, together with their health and social care professionals [21,42]. In our study, we added the literacy assessment before reaching a collective decision. The assessment enabled us to make sure our participants had enough knowledge regarding infertility and fertility preservation before making a decision. The impact of the health literacy intervention on decision regret and psychological changes merits future research.

\section{Limitations}

There were several challenges during the development of the website. The patient's psychological burden and fear increased with the severity of the cancer stage. Despite this situation, we did not provide different options for fertility preservation for patients with severer cancer stages because of insufficient evidenced-based literature. Evidence-related survival rates and recurrence rates among women with fertility preservation require more research.

With advancements in reproductive technologies, the evidence will be updated, and new options may appear periodically when the website is updated. The action research cycle provides an opportunity to modify and confirm this repeatedly, as it is quite a repetitive and lengthy process for the professionals involved.

The SDM webpages were limited to the Chinese version. Hence, we could not explore the advantages and disadvantages related to non-Chinese and non-English literature and websites. The web-based SDM regarding fertility preservation was only 
designed for women with breast cancer. Nonetheless, this study can serve as a foundation and reference for health care providers who are interested in future planning, promotion, operation, and long-term management of websites for patients with cancers other than breast cancer. The SDM website was hosted by the hospital and depended on internal technical support. All researchers in our study are responsible for ensuring a responsive-interactive website. Considering information security, patients need to provide some personal information to enter the welcome page. If the patient uses the website alone and replies to the questions on the webpage, a time delay in getting a doctor's response may increase the patient's anxiety because patients and clinicians are encouraged to visit the website together so that the doctor can answer any questions. We only evaluated the effectiveness of web-based SDM using the prepDM scale. Using the full-fledged website evaluation heuristics and exploring the long-term consequences, such as decision regret and quality of life among reproductive-age women with breast cancer, merit more study in the future.

\section{Conclusions}

With the help of the study results, we built a web-based decision-aid tool for helping reproductive-age women with breast cancer make decisions on fertility preservation. The action research provided a good structure to guide cooperation involving patients, clinicians, nurses, academic researchers, and IT engineers. The research results helped our team manage effectively and shortened the distance between theory and practice. It also helped participants who are facing the dilemma of choosing a method of fertility preservation. Based on the importance of informed consent, our website not only provided knowledge of infertility and the methods of fertility preservation but allowed us to design and test this information. It helps ensure that our participants make fertility preservation decisions with knowledge and understanding. Based on our findings, we conclude that this SDM website can indeed help patients with early-stage breast cancer make more informed decisions regarding the type of fertility preservation they would prefer to undergo. Longitudinal studies to follow up on the changes in psychological condition and subsequent pregnancy rates are needed in the future.

\section{Acknowledgments}

The observe and reflect phase was supported by the Ministry of Science and Technology, Taiwan (MOST 103-2314-B-715-005-MY3; MOST 106-2314-B-715-004 -MY2). The plan and act phase was supported by Taipei Veterans General Hospital, Taiwan (V108E-005-1) and the Ministry of Science and Technology, Taiwan (MOST 109-2314-B-715-004). Melissa Lee Cancer Foundation supported the article processing fee of the journal. We thank all of the participants in the study. We also thank Formosa Medical Editors for help with manuscript preparation.

\section{Conflicts of Interest}

None declared.

\section{Multimedia Appendix 1}

Structure of 5 main parts in the first shared decision-making webpage.

[PNG File, 342 KB-Multimedia Appendix 1]

\section{Multimedia Appendix 2}

Step 1 of the SDM process.

[PNG File, 273 KB-Multimedia Appendix 2]

\section{Multimedia Appendix 3}

Step 2 of the SDM process.

[PNG File, 330 KB-Multimedia Appendix 3]

\section{Multimedia Appendix 4}

Step 3 of the SDM process.

[PNG File, 367 KB-Multimedia Appendix 4]

\section{Multimedia Appendix 5}

Step 4 of the SDM process.

[PNG File, 245 KB-Multimedia Appendix 5]

\section{References}


1. The statistics and trends in health and welfare. Ministry of Health and Welfare Taiwan. 2018. URL: http://dep.mohw.gov.tw/ DOS/np-1714-113.html [accessed 2020-02-24]

2. Fidler MM, Gupta S, Soerjomataram I, Ferlay J, Steliarova-Foucher E, Bray F. Cancer incidence and mortality among young adults aged 20-39 years worldwide in 2012: a population-based study. Lancet Oncol 2017 Dec;18(12):1579-1589. [doi: 10.1016/s1470-2045(17)30677-0]

3. Muñoz E, Domingo J, De Castro G, Lorenzo I, García-Velasco JA, Bellver J, et al. Ovarian stimulation for oocyte vitrification does not modify disease-free survival and overall survival rates in patients with early breast cancer. Reprod Biomed Online 2019 Nov;39(5):860-867. [doi: 10.1016/j.rbmo.2019.07.003] [Medline: 31564650]

4. Campbell-Enns HJ, Woodgate RL. The psychosocial experiences of women with breast cancer across the lifespan: a systematic review. Psychooncology 2017 Nov;26(11):1711-1721. [doi: 10.1002/pon.4281] [Medline: 27648726]

5. Ruggeri M, Pagan E, Bagnardi V, Bianco N, Gallerani E, Buser K, et al. Fertility concerns, preservation strategies and quality of life in young women with breast cancer: baseline results from an ongoing prospective cohort study in selected European Centers. Breast 2019 Oct;47:85-92. [doi: 10.1016/j.breast.2019.07.001] [Medline: 31362134]

6. Howard-Anderson J, Ganz PA, Bower JE, Stanton AL. Quality of life, fertility concerns, and behavioral health outcomes in younger breast cancer survivors: a systematic review. J Natl Cancer Inst 2012 Mar 07;104(5):386-405. [doi: 10.1093/jnci/djr541] [Medline: 22271773]

7. Fertility preservation. National Cancer Institute, National Institutes of Health. URL: https://www.cancer.gov/publications/ dictionaries/cancer-terms/def/fertility-preservation [accessed 2020-05-24]

8. Martinez M, Rabadan S, Domingo J, Cobo A, Pellicer A, Garcia-Velasco JA. Obstetric outcome after oocyte vitrification and warming for fertility preservation in women with cancer. Reprod Biomed Online 2014 Dec;29(6):722-728. [doi: 10.1016/j.rbmo.2014.09.002] [Medline: 25444506]

9. Oktay K, Harvey BE, Loren AW. Fertility preservation in patients with cancer: ASCO clinical practice guideline update summary. J Oncol Pract 2018 Jun;14(6):381-385. [doi: 10.1200/jop.18.00160]

10. Srikanthan A, Amir E, Bedard P, Giuliani M, Hodgson D, Laframboise S, et al. Fertility preservation in post-pubescent female cancer patients: a practical guideline for clinicians. Mol Clin Oncol 2018 Jan;8(1):153-158 [FREE Full text] [doi: 10.3892/mco.2017.1486] [Medline: 29387409]

11. Lambertini M, Moore HC, Leonard RC, Loibl S, Munster P, Bruzzone M, et al. Gonadotropin-releasing hormone agonists during chemotherapy for preservation of ovarian function and fertility in premenopausal patients with early breast cancer: a systematic review and meta-analysis of individual patient-level data. J Clin Oncol 2018 Jul 01;36(19):1981-1990. [doi: 10.1200/jco.2018.78.0858]

12. Hsieh PL, Huang SM, Chien LY, Lee CF, Hsiung Y, Tai CJ. Risk-benefit perception of pregnancy among breast cancer survivors. Eur J Cancer Care (Engl) 2018 Mar;27(2):e12696. [doi: 10.1111/ecc.12696] [Medline: 28440587]

13. Mehrabi E, Hajian S, Simbar M, Hoshyari M, Zayeri F. The lived experience of Iranian women confronting breast cancer diagnosis. J Caring Sci 2016 Mar;5(1):43-55 [FREE Full text] [doi: 10.15171/jcs.2016.005] [Medline: 26989665]

14. Villar RR, Fernández SP, Garea CC, Pillado MTS, Barreiro VB, Martín CG. Quality of life and anxiety in women with breast cancer before and after treatment. Rev Lat Am Enfermagem 2017 Dec 21;25:e2958 [FREE Full text] [doi: 10.1590/1518-8345.2258.2958] [Medline: 29267541]

15. Tsaras K, Papathanasiou I, Mitsi D, Veneti A, Kelesi M, Zyga S, et al. Assessment of depression and anxiety in breast cancer patients: prevalence and associated factors. Asian Pac J Cancer Prev 2018 Jun 25;19(6):1661-1669 [FREE Full text] [doi: 10.22034/APJCP.2018.19.6.1661] [Medline: 29938451]

16. Bártolo A, Santos IM, Valério E, Monteiro S. Depression and health-related quality of life among young adult breast cancer patients: the mediating role of reproductive concerns. J Adolesc Young Adult Oncol 2020 Jun;9(3):431-435. [doi: 10.1089/jayao.2019.0144] [Medline: 32208042]

17. Ussher JM, Parton C, Perz J. Need for information, honesty and respect: patient perspectives on health care professionals communication about cancer and fertility. Reprod Health 2018 Jan 05;15(1):2 [FREE Full text] [doi:

10.1186/s12978-017-0441-z] [Medline: 29304873]

18. Huang SM, Tseng LM, Lai JC, Lien PJ, Chen PH. Infertility-related knowledge in childbearing-age women with breast cancer after chemotherapy. Int J Nurs Pract 2019 Oct;25(5):e12765. [doi: 10.1111/ijn.12765] [Medline: 31313445]

19. Elwyn G, Laitner S, Coulter A, Walker E, Watson P, Thomson R. Implementing shared decision making in the NHS. BMJ 2010 Oct 14;341:c5146. [doi: 10.1136/bmj.c5146] [Medline: 20947577]

20. Elwyn G, Frosch DL, Kobrin S. Implementing shared decision-making: consider all the consequences. Implement Sci 2016 Aug 08;11(1):114 [FREE Full text] [doi: 10.1186/s13012-016-0480-9] [Medline: 27502770]

21. Stiggelbout AM, Pieterse AH, De HJCJM. Shared decision making: concepts, evidence, and practice. Patient Educ Couns 2015 Oct;98(10):1172-1179. [doi: 10.1016/j.pec.2015.06.022] [Medline: 26215573]

22. Truglio-Londrigan M, Slyer JT. Shared decision-making for nursing practice: an integrative review. Open Nurs J 2018 Jan;12(1):1-14 [FREE Full text] [doi: 10.2174/1874434601812010001] [Medline: 29456779]

23. Chang HL, Li FS, Lin CF. Factors influencing implementation of shared medical decision making in patients with cancer. Patient Prefer Adherence 2019 Nov;13:1995-2005. [doi: 10.2147/ppa.s217561] 
24. Wiener RS, Koppelman E, Bolton R, Lasser KE, Borrelli B, Au DH, et al. Patient and clinician perspectives on shared decision-making in early adopting lung cancer screening programs: a qualitative study. J Gen Intern Med 2018 Jul;33(7):1035-1042 [FREE Full text] [doi: 10.1007/s11606-018-4350-9] [Medline: 29468601]

25. Zdenkowski N, Butow P, Tesson S, Boyle F. A systematic review of decision aids for patients making a decision about treatment for early breast cancer. Breast 2016 Apr;26:31-45. [doi: 10.1016/j.breast.2015.12.007] [Medline: 27017240]

26. Kemertzis MA, Ranjithakumaran H, Hand M, Peate M, Gillam L, McCarthy M, et al. Fertility Preservation Toolkit: a clinician resource to assist clinical discussion and decision making in pediatric and adolescent oncology. J Pediatr Hematol Oncol 2018;40(3):e133-e139. [doi: 10.1097/mph.0000000000001103]

27. Speller B, Metcalfe K, Kennedy ED, Facey M, Greenblatt E, Scheer AS, et al. The "Begin Exploring Fertility Options, Risks and Expectations" (BEFORE) decision aid: development and alpha testing of a fertility tool for premenopausal breast cancer patients. BMC Med Inform Decis Mak 2019 Oct 28;19(1):203. [doi: 10.1186/s12911-019-0912-y]

28. Garvelink MM, ter Kuile MM, Fischer MJ, Louwé LA, Hilders CGJM, Kroep JR, et al. Development of a decision aid about fertility preservation for women with breast cancer in The Netherlands. J Psychosom Obstet Gynaecol 2013 Dec;34(4):170-178. [doi: 10.3109/0167482X.2013.851663] [Medline: 24188788]

29. Fertility. Livestrong. URL: https://www.livestrong.org/what-we-do/program/fertility [accessed 2019-10-03]

30. Cordeiro L, Soares CB. Action research in the healthcare field. JBI Database System Rev Implement Rep 2018 Apr;16(4):1003-1047. [doi: 10.11124/jbisrir-2016-003200]

31. Bradbury H, Lifvergren S. Action research healthcare: focus on patients, improve quality, drive down costs. Healthc Manage Forum 2016 Nov;29(6):269-274. [doi: 10.1177/0840470416658905] [Medline: 27770047]

32. de Wit M, Beurskens A, Piškur B, Stoffers E, Moser A. Preparing researchers for patient and public involvement in scientific research: development of a hands-on learning approach through action research. Health Expect 2018 Aug;21(4):752-763 [FREE Full text] [doi: 10.1111/hex.12671] [Medline: 29418053]

33. Lee TI, Sheu SJ, Chang HC, Hung YT, Tseng LM, Chou SS, et al. Developing a web-based comic for newly diagnosed women with breast cancer: an action research approach. J Med Internet Res 2019 Feb 04;21(2):e10716 [FREE Full text] [doi: 10.2196/10716] [Medline: 30714947]

34. Hung YT, Wu CF, Liang TH, Chou SS, Chen GL, Wu PN, et al. Developing a decision-aid website for breast cancer surgery: an action research approach. J Med Internet Res 2019 Feb;21(2):e10404. [doi: 10.2196/10404]

35. Bennett C, Graham ID, Kristjansson E, Kearing SA, Clay KF, O'Connor AM. Validation of a preparation for decision making scale. Patient Educ Couns 2010 Jan;78(1):130-133. [doi: 10.1016/j.pec.2009.05.012] [Medline: 19560303 ]

36. The SHARE approach. Agency for Healthcare Research and Quality. 2019. URL: https://www.ahrq.gov/health-literacy/ curriculum-tools/shareddecisionmaking/index.html [accessed 2020-06-24]

37. Taiwan internet report. Taiwan Network Information Center. 2020. URL: https://twnic.tw/stat n.php [accessed 2020-05-24]

38. Huang SM, Tseng LM, Lai JC, Tsai YF, Lien PJ, Chen PH. Impact of symptom and social support on fertility intention in reproductive-age women with breast cancer. Clin Nurs Res 2020 Jul;29(6):411-418. [doi: 10.1177/1054773818770814] [Medline: 29682988]

39. Shared decision-making tool for fertility preservation. Comprehensive Breast Health Center Taipei Veterans General Hospital. URL: http://vghtpe-cbhc.sdmcare.me/healthEducation [accessed 2020-06-06]

40. Wigfall LT, Tanner AH. Literacy and health-care engagement as predictors of shared decision-making among adult information seekers in the USA: a secondary data analysis of the Health Information National Trends Survey. J Cancer Educ 2018 Feb;33(1):67-73. [doi: 10.1007/s13187-016-1052-z] [Medline: 27251634]

41. Wang MJ, Hung LC, Lo YT. Glycemic control in type 2 diabetes: role of health literacy and shared decision-making. Patient Prefer Adherence 2019 May;13:871-879. [doi: 10.2147/ppa.s202110]

42. Chew-Graham CA. Focus on shared decision-making. Health Expect 2017 Dec;20(6):1181-1182 [FREE Full text] [doi: 10.1111/hex.12654] [Medline: 29145699]

\section{Abbreviations}

IT: information technology

PrepDM: Preparation for Decision-Making scale

SDM: shared decision making 
Edited by R Kukafka; submitted 24.10.20; peer-reviewed by S Sabarguna, A Abubakar; comments to author 28.12.20; revised version received 08.01.21; accepted 04.02.21; published 17.03.21

Please cite as:

Tseng LM, Lien PJ, Huang CY, Tsai YF, Chao TC, Huang SM

Developing a Web-Based Shared Decision-Making Tool for Fertility Preservation Among Reproductive-Age Women With Breast Cancer: An Action Research Approach

J Med Internet Res 2021;23(3):e24926

URL: https://www.jmir.org/2021/3/e24926

doi: $\underline{10.2196 / 24926}$

PMID: 33729164

CLing-Ming Tseng, Pei-Ju Lien, Chen-Yu Huang, Yi-Fang Tsai, Ta-Chung Chao, Sheng-Miauh Huang. Originally published in the Journal of Medical Internet Research (http://www.jmir.org), 17.03.2021. This is an open-access article distributed under the terms of the Creative Commons Attribution License (https://creativecommons.org/licenses/by/4.0/), which permits unrestricted use, distribution, and reproduction in any medium, provided the original work, first published in the Journal of Medical Internet Research, is properly cited. The complete bibliographic information, a link to the original publication on http://www.jmir.org/, as well as this copyright and license information must be included. 